\title{
Paisaje patrimonial y riesgo ambiental. Reocupación cultural y turística del espacio postminero en Lota, Chile ${ }^{1}$
}

\author{
María Isabel López Meza² y Claudia Vidal Gutiérrez ${ }^{3}$
}

\begin{abstract}
RESUMEN
Los espacios mineros decimonónicos y de principios del siglo $\mathrm{XX}$, poseen cada vez mayor reconocimiento entre planificadores, como una particular forma de patrimonio. Sus impulsores señalan la importancia de los vestigios mineros como testimonios de la revolución industrial, y su significancia para la identidad local. De igual modo, han promovido su reutilización para el turismo cultural. Por otra parte, previo a su reutilización, diversos riesgos ambientales presentes en estos territorios deben ser considerados. A partir del ex poblado carbonífero de Lota, el artículo identifica los principales elementos del patrimonio minero y los riesgos ambientales asociados. Los resultados permiten constatar la profunda vinculación existente entre las áreas de mayor valor patrimonial y las de riesgo ambiental y, por lo tanto, la necesidad de un abordaje integrado de los objetivos de puesta en valor y los de remediación. Todo lo anterior, como requisito para una reutilización sostenible del espacio minero en la fase postextractiva.
\end{abstract}

Palabras clave: Patrimonio minero, riesgo ambiental, Lota.

\begin{abstract}
Nineteenth century mining areas have increasingly gained recognition as a particular form of industrial heritage among planners. Advocators point out the importance of mining remains as a testimony of industrial revolution, as well as its significance for local identity; and have promoted mining tourism reuse. On the other hand, various environmental problems should be considered previously. Using the former coal settlement of Lota in Chile, the article identifies the main elements of mining heritage; and the associated natural and manmade risk. The results verify the profound linkages between heritage value and environmental risk in former mining areas; thus stressing the need of an integrated approach to: the remediation of environmental risk, and the preservation of mining landscape; as a requirement for sustainable reuse.
\end{abstract}

Key words: mining heritage, environmental risk, Lota.

Proyecto INNOVA Biobío: "Dinamización turística de la zona minera de Lota". Artículo recibido el 27 de mayo de 2011, aceptado el 15 de enero de 2012 y corregido el 3 de febrero de 2012
2 Departamento de Planificación y Diseño Urbano, Universidad del Bío-Bío (Chile).E-mail: mlopez@ubiobio.cl 3 Pedagogía en Historia y Geografía, Universidad de San Sebastián (Chile). E-mail: claudia.vidal@uss.cl 
La valoración del patrimonio minero constituye un nicho relativamente reciente del patrimonio industrial, cuyos orígenes se remontan a la década de 1960 en Inglaterra. Los impulsores de este tipo de patrimonio, señalan su importancia para la identidad local y su valor testimonial. Los vestigios minero-industriales evidencian el paso desde una época y una economía basada en la agricultura, a otra época basada en la producción industrial. Junto con la valoración de estos vestigios, surge el turismo de patrimonio minero, como una vertiente particular dentro del turismo cultural. Es así como se han desarrollado diversos museos o parques mineros, que proponen la reutilización de los vestigios con un sentido cultural y turístico ${ }^{4}$. Si bien entre las décadas de 1960 y 1980 surgen diversos 'parques o museos mineros ${ }^{5}$, el interés de los investigadores por estudiar este fenómeno como una alternativa para la revitalización de ex áreas industriales, es mucho más reciente. Normalmente, cuando se habla de patrimonio minero, se incluyen en este concepto tanto las señas físicas de esta actividad (las instalaciones, los asentamientos mineros, las infraestructuras de transportes, las galerías subterráneas y las cortas, etc.), como el legado cultural intangible de la época minera (las fiestas mineras, celebraciones y la cohesión social, entre otros).

Por otra parte, junto con este legado que se valora, es indudable que la minería ha generado graves impactos ambientales: en el suelo, los acuíferos y la atmósfera. Con el cierre de las minas, estos impactos, lejos de aminorarse suelen agravarse, ante un débil marco legislativo para la fase postminera (Clark, 2005). Es así como, desde el punto de vista ambiental, es posible distinguir tres escenarios posibles tras el cierre de las minas. El primero y más ampliamente reconocido como el más deficiente, es el abandono de las instalaciones. El segundo, es la realización de acciones de remediación ambiental, orientadas a devolver el lugar a su condición

\footnotetext{
4 Ironbridge Gorge, Beamish Museum, National Coal Mining Museum en Inglaterra; Museo Minero Riotinto, Museo Minero del Entrego en España; Zeche Zollverein en Alemania; y Lewarde en Francia, entre otros

5 Principalmente en Inglaterra y Alemania.
}

previa a la instalación de la actividad minera. Este enfoque aborda la remediación ambiental de los impactos mineros; sin embargo, presenta el problema de borrar la evidencia, de la importancia que tuvo esta industria para el desarrollo de la localidad (Cole, 2004) y para su particular 'sentido de lugar'6 (CansenVerbeke, 1999: 74; y Leary \& Choles, 2000: 52). De ahí que el tercer escenario es considerado en este artículo como el más apropiado. Este es: la planificación de acciones de remediación, pero al mismo tiempo, la valoración de las señas de la historia minera sobre el paisaje.

A partir de este enfoque, el presente artículo explora los riesgos naturales y antrópicos del área carbonífera de Lota Alto, así como los impactos ambientales generados por la minería; y propone acciones destinadas a la reutilización cultural y turística del área. Estas acciones consideran - de manera sistémicatanto la mitigación del riesgo como la puesta en valor del paisaje patrimonial minero.

Al inicio del artículo se precisan los antecedentes teóricos de la investigación, y se presenta el caso de estudio. Luego, los resultados se organizan en cuatro partes. En la primera, se introducen los principales componentes del patrimonio minero; en la segunda, se identifican los siguientes aspectos. Por un lado, las áreas y tipos de riesgos naturales y antrópicos existentes; y por otro, los efectos del último terremoto, en tanto estos se explican tanto por procesos naturales como por cambios ambientales provocados por la minería. Finalmente, en la tercera parte, se presenta una propuesta integrada de valorización y remediación ambiental del paisaje patrimonial minero.

\section{Valores y elementos patrimoniales del paisaje minero}

Dentro del concepto de patrimonio minero, es posible distinguir tres categorías. La primera, conocida como patrimonio geológi-

\footnotetext{
6 Sense of place, en el inglés original.
} 
co minero, se refiere a una combinación del patrimonio "artificial", que alude al legado construido; y el "natural", referido a las formaciones geológicas que son evidenciadas a raíz de la minería. Estas formaciones, además de su valor contemplativo, tienen un valor científico y didáctico, en tanto permiten comprender e ilustrar procesos de formación y evolución del planeta (Carvajal, 2003).

La segunda categoría, conocida como patrimonio minero metalúrgico, apunta a reconocer el legado físico e intangible de la actividad extractiva en ciertas comarcas. Se incluyen en esta categoría no solo las actividades extractivas propiamente tales, sino también otras actividades industriales cuyo fin último es la producción del metal. Este tipo de patrimonio es también considerado un ejemplo paradigmático de patrimonio cultural y natural, por la estrecha vinculación que existe entre el lugar de explotación y el patrimonio geológico que lo sostiene (AyalaCarcedo, 2000). La minería pone al descubierto estructuras y formaciones geológicas, que constituyen, en algunos casos, elementos patrimoniales por sí mismos ${ }^{7}$. Es así como "esta componente de valor histórico social, junto a la tecnológica y la natural, conforman la valoración de este tipo de patrimonio" (Ayala-Carcedo, 2000: 34). En términos históricos, se destaca la contribución de esta actividad al desarrollo económico de los países que lo han practicado y al despegue industrial del siglo XIX; la expansión de las exportaciones; y, por último, el desarrollo del sindicalismo en el mundo. En términos socioculturales se destaca su dimensión inmaterial, señalando que estos lugares "representan un conjunto de prácticas y organizaciones sociales y económicas en el campo productivo (...) que conforman una dimensión social que no suele tener el Patrimonio Natural..." (AyalaCarcedo, 2000: 33).

Finalmente, una tercera categoría asociada al tema minero es la de paisaje. Desde esta perspectiva, dos conceptos relevantes son los de "paisaje cultural" y "paisaje mine-

\footnotetext{
7 Ayala-Carcedo (2000) destaca como ejemplo de lo anterior el caso de los yacimientos paleontológicos de Verdeña (Palencia) o de Riotinto, ambos en España.
}

ro". De acuerdo a Sabaté (2004), un paisaje cultural es un ámbito geográfico que contiene valores estéticos y culturales, derivados de su asociación a un evento, una actividad o un personaje histórico. Basándose en la definición de la Convención Europea del Paisaje ${ }^{8}$, Puche define paisaje minero como "cualquier parte del territorio que haya soportado la actividad extractiva de minerales o rocas, sea cual sea su estado" (2003: 61). Y señala que este concepto engloba valores estéticos, sociales, culturales, históricos, ecológicos, y económicos, entre otros (Puche, 2003: 60) ${ }^{9}$. Describiendo las relaciones entre paisaje minero e industrial, se señala que -producto de las características de la actividad minera- el paisaje se ve modificado en la zona de extracción tanto por las instalaciones productivas (mineras, industrias transformadoras, y estructuras de transporte) como por los asentamientos mineros. De esta manera, "el paisaje minero se convierte en paisaje industrial (industrial landscape) y en paisaje urbano (townscape) (Puche, 2003: 65).

A partir de la perspectiva conservacionista y de la sostenibilidad, ${ }^{10}$ así como de la revisión de diversos investigadores en el tema específico del turismo de patrimonio minero (Ayala-Carcedo, 2000; Carvajal, 2003: 39; Cole, 2004; Cansen-Verbeke, 1999: 74; y Leary \& Choles, 2000: 52), es posible identificar dos principios para una recuperación sostenible de estos territorios. En primer lugar, la importancia de su recuperación ecológica, y de la prevención y mitigación del riesgo am-

8 Florencia (Italia), 20 de octubre de 2000.

9 Puche señala que la $1^{\text {a }}$ vez que se utilizó oficialmente este término fue en el año 1993, con ocasión de la Convención de Cultura de la Comunidad de Murcia. Sin embargo -también de acuerdo este autor- es a partir de la I Sesión Científica de la Sociedad Española de Patrimonio Geológico y Minero o SEDPGYM, en 1996, Almadén, 21-22 de octubre de 1996, cuando se presentan diversas ponencias que destacan la profunda transformación del paisaje español a raíz de la actividad minera; y este concepto empieza a estar más presente.

10 Por perspectiva 'conservacionista' aludimos fundamentalmente a la perspectiva expresada en la Carta Internacional del Turismo Cultural, y que ha sido adoptada por el ICOMOS. Por perspectiva de la sostenibilidad a aquella que ha acuñado el concepto de turismo sostenible y que ha sido adoptada por la Organización Mundial de Turismo (OMT) y la English Tourist Board (ETB). 
biental. Y en segundo lugar, la importancia de conservar las trazas de la actividad minera, como elementos importantes de la identidad del lugar. Este último principio toma partido en la polémica que existe entre quienes se manifiestan a favor de eliminar todas las trazas de la actividad extractiva, y quienes se oponen, señalando que, hacerlo, conlleva el peligro de borrar importantes eslabones de la historia local.

\section{Impactos ambientales específicos de la actividad minero-industrial}

El análisis ambiental incluye la consideración de los riesgos ambientales, tanto naturales como antrópicos, y de los principales conflictos ambientales presentes en un área patrimonial minera.

El riesgo natural es definido como la probabilidad de ocurrencia en un lugar dado y en un momento determinado, de un fenómeno natural potencialmente peligroso para la comunidad, y susceptible de causar daño a las personas y a sus bienes. Más específicamente, la Organización de las Naciones Unidas (ONU) (Ayala-Carcedo, 1993) lo define como el producto de la probabilidad de ocurrencia de una amenaza o peligro natural, por la vulnerabilidad, en tanto por uno, y la exposición. La peligrosidad o amenaza se entiende como un fenómeno natural, cuya dinámica puede desbordar sus umbrales más frecuentes de intensidad, magnitud y localización, pudiendo ocasionar daños a las personas y a sus bienes (Ayala-Carcedo et al., 1988). El sistema sobrepasa, entonces, un umbral, para llegar a un nuevo régimen dinámico. Estos valores pueden ser artificialmente modificados por el hombre, lo que podría desencadenar un desastre, que en condiciones naturales habría tardado más en producirse. Por lo tanto, las adaptaciones del medio físico realizadas por el hombre para la ocupación urbana o industrial del territorio, generalmente contribuyen a la ocurrencia de desastres (Mardones y Vidal, 2001).

Los riesgos antrópicos, en tanto, se encuentran asociados al desarrollo tecnológico, donde la responsabilidad del hombre es prácticamente total. Demandas específicas, vinculadas al incremento en los niveles de consumo y al mejoramiento de los sistemas de transporte, pueden derivar en el uso de tecnologías capaces de generar desastres. Las áreas de mayor riesgo potencial son las zonas en donde se concentra: la población, el transporte de sustancias peligrosas y las industrias (Larraín, 1994). Entre los riesgos antrópicos típicamente generados por la actividad minera podemos mencionar los siguientes:

- generación de incendios, dada la condición inflamable y autocomburente de las pilas de tosca;

- deslizamientos, producto del movimiento de desechos no compactados; y

- subsidencia diferencial del terreno, dada la presencia de galerías subterráneas.

En cuanto a los impactos ambientales generados por la minería del carbón, se pueden identificar los siguientes:

- En el suelo y la topografía: eliminación de la cobertura vegetal; modificación de la topografía; y contaminación del suelo, por acumulación de desechos resultantes de la actividad carbonífera.

- En el sistema hídrico: contaminación de los ríos, napas subterráneas y/o humedales (producto de la eliminación de aguas de las minas superficiales o subterráneas); interrupción de la continuidad del acuífero local, producto de la remoción de los estratos de piedra; y la alteración de las características hidráulicas y de calidad del agua, producto del material de relleno y represamiento de ríos.

- En la atmósfera: contaminación del aire producto de material particulado proveniente de explosiones, excavaciones, movimiento de tierras, transporte, transferencia de materiales, erosión eólica de la tierra floja durante la extracción superficial, o cualquier operación que ocurra en la superficie de las minas subterráneas.

\section{Metodología y métodos de investigación}

La metodología de la investigación consideró las siguientes fases. En la primera, se identificaron las áreas y los elementos de 
mayor valor patrimonial del área de estudio. Esta identificación se realizó a partir de información extraída de Aravena y Betancur (1995), Muñoz et al. (2005) y SURPLAN (2005), y fue corroborada en diversos talleres realizados con la comunidad ${ }^{11}$. En la segunda fase, se identificaron las zonas de riesgo natural y antrópico asociadas al área patrimonial minera; y en especial aquellas derivadas de la actividad extractiva. La definición de las áreas de riesgo se realizó constatando y actualizando en terreno el diagnóstico del Plan Regulador vigente. Finalmente, en la tercera fase, se definieron unidades homogéneas de paisaje; y se identificaron las principales medidas a aplicar en cada una de ellas, para una reutilización (cultural y turística) sostenible. Esto último se realizó a partir de un análisis comparativo entre los valores patrimoniales y las restricciones ambientales presentes en cada unidad.

11 En el marco del Proyecto INNOVA Biobío "Dinamización Turística de la Zona Minera de Lota", en el cual participaron las autoras del artículo. Los talleres fueron realizados con representantes del ámbito cultural y artístico de Lota, en junio 2010, en el Centro Cultural Pabellón 83 de Lota.
Se contemplaron los siguientes métodos de investigación: i) análisis de bibliografía especializada; ii) análisis de cartografías del Plan Regulador vigente y otros estudios; iii) fotointerpretación de imágenes satelitales y constatación en terreno; y iv) entrevistas con actores clave ${ }^{12}$. Una vez recopilada la información, esta se ingresó a SIG ArcView y se espacializaron las áreas de peligrosidad natural y de riesgos antrópicos, calculándose la superficie patrimonial expuesta, para cada uno de los riesgos.

\section{El caso de estudio: la ex zona minera de Lota}

La minería del carbón se desarrolló fundamentalmente en la Región del Biobío; en el borde costero entre Tomé y Lebu, conocida como golfo de Arauco o cuenca del carbón (Figura $\mathrm{N}^{\circ} 1$ ).

\footnotetext{
12 Se entrevistó al asesor urbano y al encargado de medio ambiente de la Municipalidad de Lota.
}

Mapa de ubicación de la cuenca del carbón, Chile

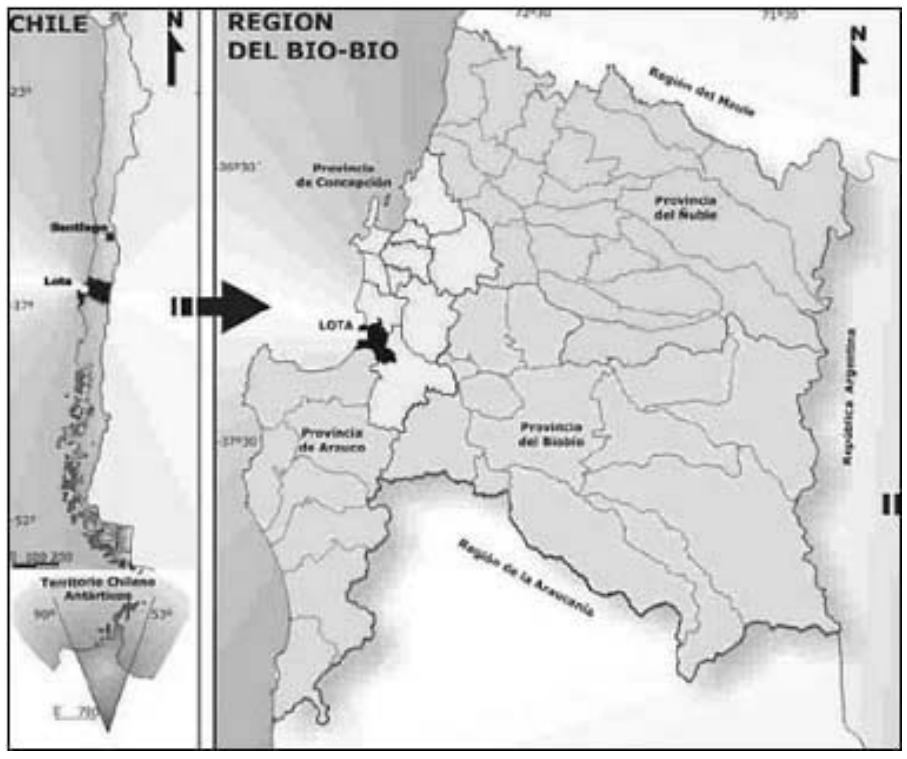

Fuente: Laboratorio de Estudios Urbanos (LEU), Universidad de Bío-Bío. 
Figura $\mathrm{N}^{\circ} 2$

Vista aérea de Lota Alto y Lota Bajo

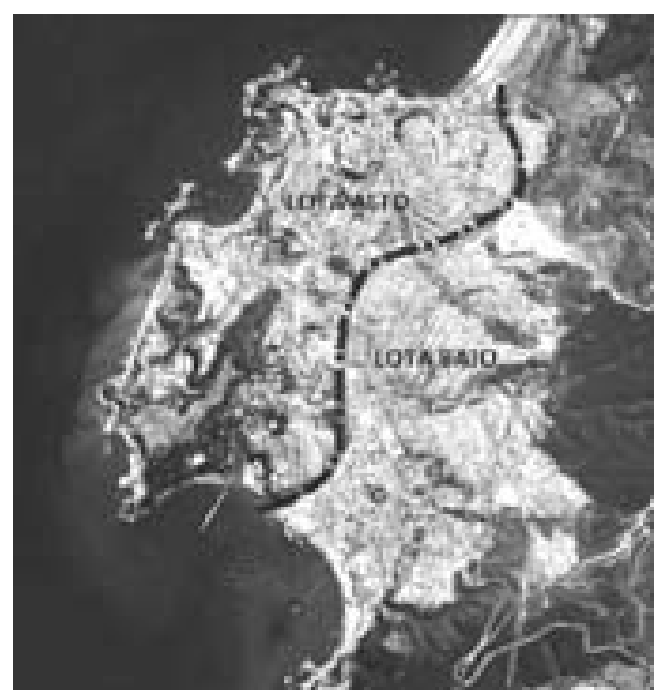

Fuente: Elaborado a partir de imagen extraída de Google Earth.

Dentro del contexto de la minería, existe un amplio consenso en cuanto a la importancia de esta área, como la zona geográfica que lideró la producción carbonífera en Chile, y a cuyo nivel de producción no se le acercaba ninguna otra zona del país ${ }^{13}$. Dentro del golfo de Arauco se destacaron las labores iniciadas el año 1850 por Matías Cousiño, en la bahía de Lota.

La ciudad de Lota surgió como un pequeño asentamiento prehispánico ubicado en la actual localidad de Colcura, y cuya actividad principal era la pesca artesanal y la agricultura $^{14}$. Sin embargo, con el comienzo de la República a principios del siglo XIX, se inició la explotación del carbón, y la ciudad adquirió importancia a nivel regional y nacional ${ }^{15}$. A

\footnotetext{
${ }^{13} \mathrm{Si}$ bien en la zona de Magallanes la explotación también se inició a mediados del siglo XIX, la actividad no se desarrolló con la continuidad y magnitud de la zona de Arauco.

${ }^{14}$ De ahí el nombre original de la ciudad, "Louta", que significa en lengua nativa pequeño lugar o pequeño caserío (Astorquiza, 1929).

15 Importancia que contrasta con la escasa relevancia nacional o regional de Lota durante el periodo colonial, la que se manifestó incluso en una tendencia al decrecimiento, a raíz de las complejas circunstancias producidas por la Guerra de Arauco.
}

partir de la segunda mitad del siglo XIX, la llegada al país de vapores que utilizaban carbón como combustible, fue otro impulso para el desarrollo industrial de la comuna. La explotación a mayor escala se inició con la adquisición de la hacienda Colcura, por parte del empresario chileno Matías Cousiño. A partir de este momento la actividad extractiva -que se extendió en la zona por un periodo aproximado de 140 años- transformó completamente el poblado, el cual llegó a ser, a fines de ese mismo siglo, uno de los complejos industriales más grandes del país ${ }^{16}$ (Ortega, 1982).

Actualmente, la ciudad de Lota se estructura en dos áreas claramente reconocibles: Lota Bajo, en la planicie costera; y Lota Alto, en los cerros al noroeste de la cordillera de Nahuelbuta e inmediatos al mar (Figura $N^{\circ} 2$ ). Esta última zona corresponde a la ubicación original del histórico asentamiento minero fundado el año 1851 por Matías Cousiño, y la que concentra la mayor parte del legado urbano y arquitectónico, vinculado a la actividad minera. En la década del 60, la menor competitividad del carbón frente al petróleo, junto a las tensiones sindicales y políticas en el país, provocaron que las expectativas del negocio carbonífero disminuyeran en forma importante, factor que contribuyó a la estatización de las grandes minas. A pesar de ello, tras la crisis mundial del carbón, se produjo el cierre definitivo de las minas de Lota el año 1997.

El área de estudio incluye el histórico asentamiento minero, ubicado en la parte más alta de la meseta, y las ex zonas industriales ubicadas a lo largo del borde costero. Para la definición de los límites, se consideraron los siguientes antecedentes: la propuesta de Área de Conservación de Lota (SURPLAN, 2005) ${ }^{17}$; y el estudio de Muñoz et al. (2005), que identifica los principales lugares y elementos del patrimonio en Lota.

\footnotetext{
16 Junto con la ciudad vecina de Coronel.

17 Estudio encargado por el Ministerio de Vivienda y Urbanismo (MINVU) para incorporar Áreas de Conservación al Plan Regulador Comunal. Los inmuebles de valor patrimonial fueron registrados, evaluados y jerarquizados mediante la aplicación de una pauta de cuatro parámetros: arquitectónico, histórico, económico y social. El detalle de los inmuebles patrimoniales se revisa en el punto siguiente.
} 


\section{Áreas y elementos del patrimonio minero en Lota}

Desde el punto de vista del legado tangible de Lota Alto, es posible distinguir las siguientes categorías principales de elementos: i) las instalaciones industriales y el muelle, y ii) el asentamiento minero. Las instalaciones industriales comprenden las zonas donde se ubican los piques y chiflones: Chiflón del Diablo, pique Grande o Luis, pique Carlos y pique Alberto. Estos se ubican a lo largo del borde costero, en una situación de privilegio con respecto a las vistas de la playa y el mar. Dentro de estas instalaciones se distinguen los piques, como los elementos representativos de la imagen urbana y paisajística de Lota. Los piques, por sus dimensiones y particular silueta, constituyen los iconos de la historia más reciente de la industria del carbón. Otro elemento relevante es el muelle, tanto por su escala y aporte estético como por su importancia histórica (Figura №3).

Con respecto al valor patrimonial del asentamiento minero, se destaca particularmente el modelo urbano aplicado como reinterpretación del modelo de la villa industrial desarrollado en Inglaterra en el siglo XVIII; y luego en Francia como Cité Ouvrière a partir del siglo XIX; en Alemania como Arbeiten Siedlungen; en España como Colonia Industrial; y más tarde en los EE.UU. como Company Towns.

Asimismo, se destacan diversos valores morfológicos y espaciales intrínsecos. En primer lugar, la excepcionalidad de su trama urbana. A diferencia de la trama convencional aplicada en Hispanoamérica, la trama en Lota Alto no se configura por medio de una cuadrícula de calles y plazas, sino por una serie de volúmenes edificados de gran homogeneidad

Figura $N^{\circ} 3$

Áreas y elementos patrimoniales en Lota Alto.

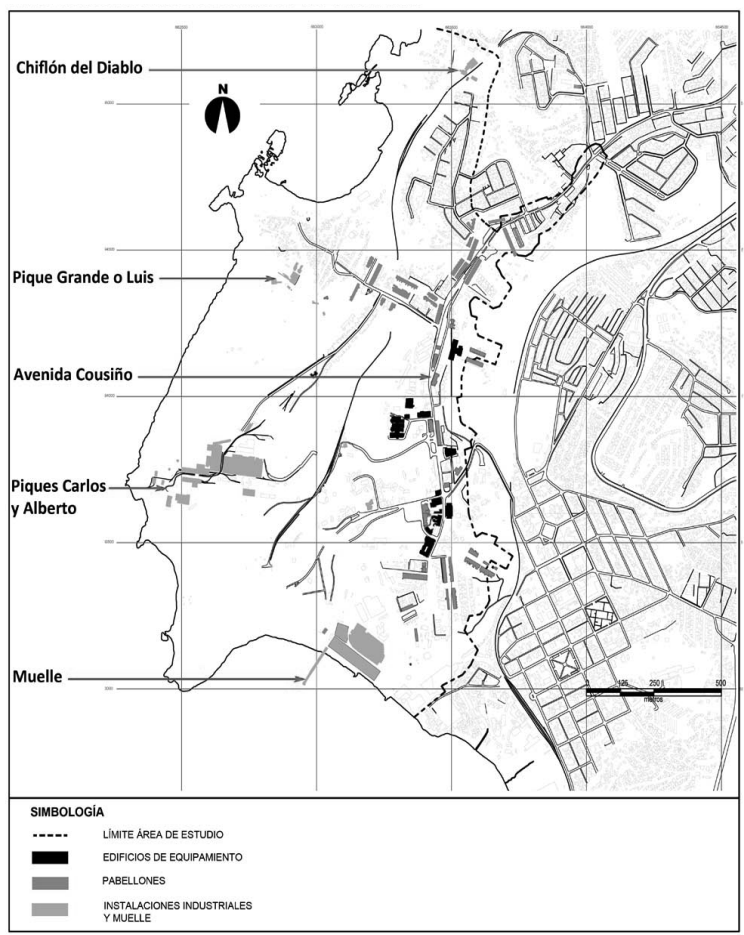

Fuente: Elaboración propia a partir de información extraída de SURPLAN (2005), Muñoz et al. (2005) y López (2010). 
(los pabellones mineros), los cuales se emplazan a lo largo de la Avda. Cousiño. En segundo lugar, su morfología urbana, que valoriza y realza la topografía del asentamiento. Es así como el eje principal (Avda. Cousiño) genera una secuencia de suaves giros y ondulaciones, que reconoce y valoriza las curvas del relieve, definiendo, de esta manera, un trazado urbano de gran coherencia con la geografía. En Lota, tanto el trazado viario como la disposición de los edificios expresa una estrecha relación con el relieve y las espectaculares vistas hacia el mar. Un tercer valor morfológico es la unidad y estructura del tejido urbano, en el cual se conjugan, armónica y complementariamente, las principales piezas arquitectónicas; conformando un todo de gran coherencia espacial. Es así como los pabellones de vivienda obrera, constituyen el telón de fondo que configura el eje Cousiño, y sobre el cual se destacan, rítmicamente, los edificios singulares de equipamiento: la escuela Thompson Mathews, la iglesia Matías Apóstol y el teatro, entre otros (Figuras $\mathrm{N}^{\circ} 4$ ).

Finalmente, sobresale también un conjunto de elementos de uso común (hornos, canchas de fútbol, lavadero, etc.) que prolongan la vida doméstica hacia el espacio público, fortaleciendo las relaciones comunitarias. Dentro del asentamiento, el estudio SURPLAN (2005) destaca diversas tipologías de espacio público de valor patrimonial. Un espacio particularmente relevante es el Parque de Lota, el cual paulatinamente sirvió para la reunión de las familias lotinas, a pesar de que estaba bajo la dirección de la empresa, que controlaba su acceso. El Parque de Lota fue diseñado por el paisajista inglés Bartlet G.O. Really. Fue construido entre los años 1862 y $1872,{ }^{18}$ para albergar el palacio de la familia Cousiño; y fue declarado Monumento Nacional el año 200919. Finalmente, con respecto al entorno geográfico, algunos lugares exteriores relevantes han sido las playas y los bosques, como lugares de encuentro de los mineros en torno a: fogatas, fiestas y actividades sindicales ${ }^{20}$. Algunos lugares específicos

\footnotetext{
${ }^{18}$ Consejo de Monumentos Nacionales (CMN).

${ }^{19}$ Según Decreto Exento 373 del 06/10/2009.

20 Un evento clave en este último sentido fue la huelga de 1920, que consistió en un multitudinario encuentro realizado en Playa Blanca.
}

mencionados por Aravena y Betancur (1995) son: la Conchilla y el cerro el Morro.

\section{Áreas de riesgo en la zona patrimonial minera de Lota}

Desde el punto de vista del riesgo, el análisis demuestra la presencia de importantes limitaciones naturales al emplazamiento humano, tales como: las fuertes pendientes, la constitución litológica del sitio urbano y las características climáticas de la zona.

\section{Riesgos naturales}

Respecto a los riesgos naturales, se identifican procesos de remoción en masa, riesgo sísmico, marejada, tsunami y erosión marina. En la Figura $\mathrm{N}^{\circ} 5$ se observa la superficie afectada por tipo de riesgo, constatándose

\section{Figura $\mathrm{N}^{\circ} 4$}

Valores morfológicos y espaciales de Lota. a) Vista de los pabellones que configuran la Avenida Cousiño; b) Vista de la iglesia desde corredor de pabellones
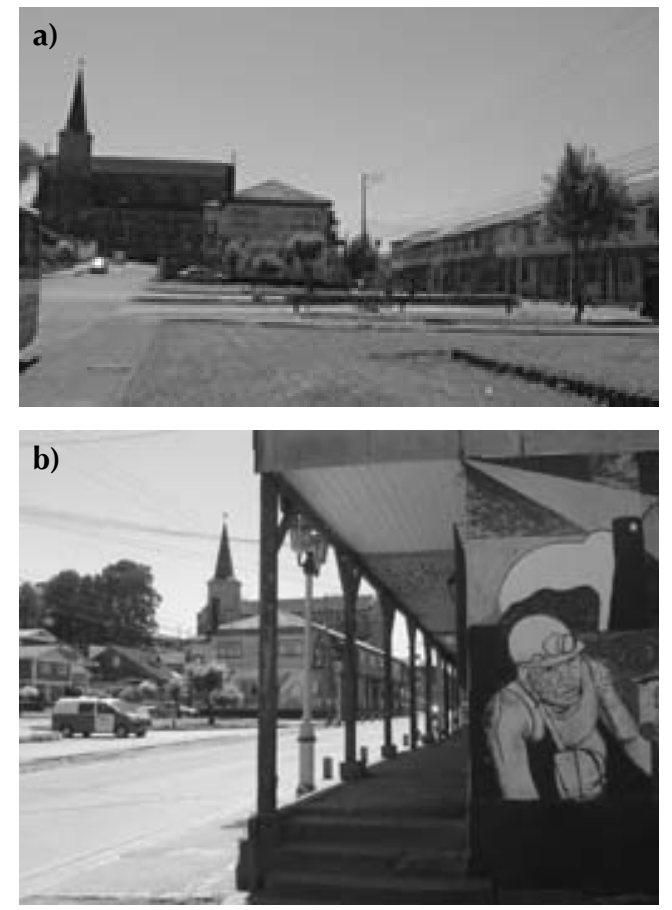

Fuente: Colección propia de las autoras. 
que los riesgos de remoción en masa y de tsunami, son los que presentan mayor superficie expuesta.

Los procesos de remoción en masa, que en este caso incluyen derrumbes y desliza- mientos, son las manifestaciones morfodinámicas más frecuentes de la inestabilidad de laderas. Los deslizamientos consisten en un descenso en masa de materiales rocosos sobre una ladera, a través de un plano (de falla, estratigráfico, contacto litológico).

Figura $N^{\circ} 5$

Superficie afectada por tipo de riesgo natural (hectáreas)

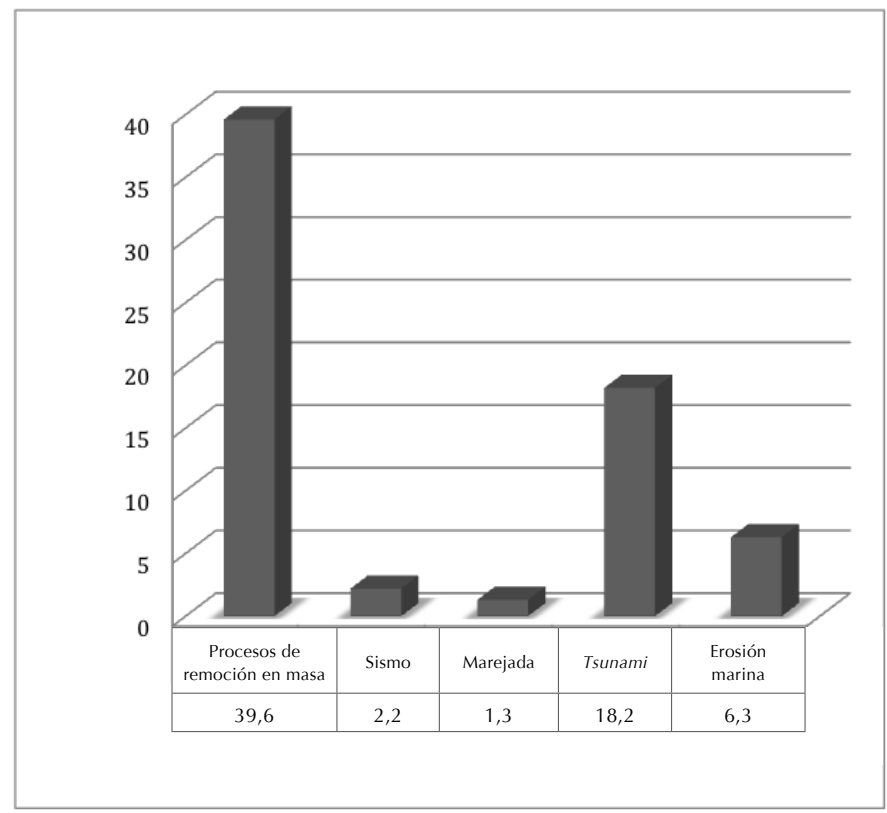

Fuente: Elaboración propia.

Cuadro $\mathrm{N}^{\circ} 1$

Matriz de evaluación de peligrosidad del riesgo de procesos de remoción en masa

\begin{tabular}{|l|l|l|l|}
\hline Evaluación & 1 & 2 & 3 \\
\hline Factores & $<20^{\circ}$ & $20-30^{\circ}$ & $>30^{\circ}$ \\
\hline Pendientes & $\begin{array}{l}\text { Terrazas, llanuras, } \\
\text { cordones litorales }\end{array}$ & $\begin{array}{l}\text { Escarpes y laderas } \\
\text { de mediano vigor, } \\
\text { cóncavas y regulares }\end{array}$ & $\begin{array}{l}\text { Escarpes y laderas } \\
\text { de gran vigor, } \\
\text { convexas }\end{array}$ \\
\hline Litología & $\begin{array}{l}\text { Roca sana, homogénea, } \\
\text { manto meteorizado, débil } \\
\text { potencia }\end{array}$ & $\begin{array}{l}\text { Roca alterada o } \\
\text { diaclasada } \\
\text { semicoherente }\end{array}$ & $\begin{array}{l}\text { Sedimentos } \\
\text { incoherentes } \\
\text { heterogéneos }\end{array}$ \\
\hline $\begin{array}{l}\text { Cobertura } \\
\text { vegetal }\end{array}$ & $>75 \%$ & $75-50 \%$ & $<50 \%$ \\
\hline
\end{tabular}

Fuente: Mardones, 1997. 
Los derrumbes, en tanto, se originan por el desplome gravitacional de una masa considerable de material rocoso, que da como resultado una acumulación caótica de rocas en el pie de vertiente (Flageollet, 1989; Gueremy, 1987; por Mardones, 1997). El Informe del Plan Regulador identifica los factores que explican la ocurrencia de este tipo de desastre en la comuna de Lota; entre ellos: variables morfométricas, morfológicas, litológicas, cobertura vegetal, condiciones climáticas, procesos hídricos e intervención humana. Las cuatro primeras variables se evalúan en el Cuadro $N^{\circ} 1$.

Los movimientos en masa obedecen a la fuerza de gravedad, en cuya acción tiene importante participación el agua líquida contenida en el suelo, y almacenada principalmente por alimentación pluvial. El umbral de intensidad de lluvia, a partir del cual se desencadenan derrumbes y deslizamientos, depende fundamentalmente del tipo de roca y de las condiciones de cobertura del suelo. Estudios realizados por Mardones et al. (1995) han comprobado que, en el Área Metropolitana de Concepción los derrumbes se intensifican cuando existen más de 100 mm de lluvia acumulada en 72 horas.

De acuerdo a lo indicado por Mardones (1997), la intervención antrópica es un importante factor morfogenético en el desencadenamiento de procesos de ladera, ya que, generalmente, realiza sus intervenciones sin valorar la pendiente umbral de manifestación de dichos procesos. Por último, los terremotos (a través de sus vibraciones) y las marejadas de temporal (por la erosión basal que origina en los acantilados) pueden ser detonantes para la ocurrencia de grandes derrumbes. Esto es precisamente lo que ocurrió con el último evento sísmico del 27 de febrero de 2010, como se explica más adelante.

En síntesis, las áreas expuestas a riesgo de remoción en masa en el área de estudio son: los escarpes de erosión y de falla con pendientes convexas superiores a $30^{\circ}$ y mantos meteorizados constituidos con sedimentos incoherentes e hidratados. Se encuentran expuestas a este riesgo importantes áreas patrimoniales, tales como: Pique Alberto, laderas del Parque Isidora Cousiño, zona del Barrio Chino y Pabellón 56. Los dos primeros se lo- calizan sobre acantilados del borde costero, por lo cual presentan, adicionalmente, una importante erosión marina (Figura $N^{\circ} 6$ ).

Los sismos son fuertes e inesperadas vibraciones de la corteza terrestre que se producen, principalmente, en los sitios de roce de placas tectónicas. En el sector investigado, los terremotos son provocados por el desplazamiento de la placa de Nazca bajo la placa Sudamericana. Se ha registrado al menos un terremoto, de magnitud superior a grado 7 por siglo, con epicentro en el sector litoral de Concepción. La magnitud del sismo se expresa en superficie con diferente intensidad, ya que múltiples factores locales pueden ampliar o disminuir la señal vibratoria.

En general, las áreas de más alto riesgo sísmico son aquellas situadas en terrenos con acumulación de material orgánico, conformadas por sedimentos fluviales o marinos de edad reciente y sectores de relleno artificial reciente, mal consolidado. Junto a diversos factores naturales ${ }^{21}$, en el caso de Lota, se debe agregar la actividad minera. En el área de estudio, el sector del muelle e instalaciones portuarias están afectados por peligrosidad alta frente al riesgo sísmico.

El riesgo de erosión marina afecta al borde costero en el sector de acantilados activos. Los roqueríos costeros están constituidos por rocas sedimentarias estratificadas e intensamente fracturadas. Estas zonas son permanentemente azotadas por las olas, experimentando en algunos sectores fluctuación de las mareas. Estos últimos, dado el nivel de erosión que presentan, su escasa cobertura vegetal y sus elevadas pendientes, generalmente presentan riesgo de remoción en masa.

\footnotetext{
21 El método de microzonificación sísmica considera dos tipos de factores para la evaluación del riesgo sísmico: por una parte la modificación que el relieve y los estratos superficiales producen en la señal vibratoria, y en segundo lugar, los efectos hídricos y morfológicos que el sismo tiene sobre los suelos (proceso de licuación, deslizamientos y derrumbes) (Mardones y Vidal, 2001).

La respuesta de un suelo a la onda sísmica y por ende los impactos que genera un sismo depende de la magnitud del terremoto, distancia al epicentro, tipo de suelo, posición de la napa freática, morfología y pendiente topográfica.
} 
Adicionalmente, la erosión generada por el mar contribuye a la saturación del suelo y a la disminución de su coherencia.

En cuanto al riesgo de tsunami este es definido como un tren de ondas, habitualmente generado por un disturbio sísmico, que impulsa y desplaza verticalmente la columna de agua. El período de las ondas puede variar desde varios minutos hasta horas. En todos los casos se propaga a gran velocidad desde la zona de origen, de manera que las olas al llegar a la costa descargan su energía con inusitada violencia, inundando y destruyendo las áreas alcanzadas. De acuerdo a Cañón y
Morales (1985), el grado de destructividad de un tsunami depende de los siguientes factores:

- La configuración de la línea costera o de la forma de la bahía.

- Las características geomorfológicas del litoral alcanzado por las olas.

- La magnitud y la profundidad focal del terremoto que lo genera y de la distancia del epicentro sísmico.

- La extensión del área del fondo marino que ha sido perturbada, así como la velocidad con la cual se lleva a cabo dicha perturbación.

- La topografía submarina.

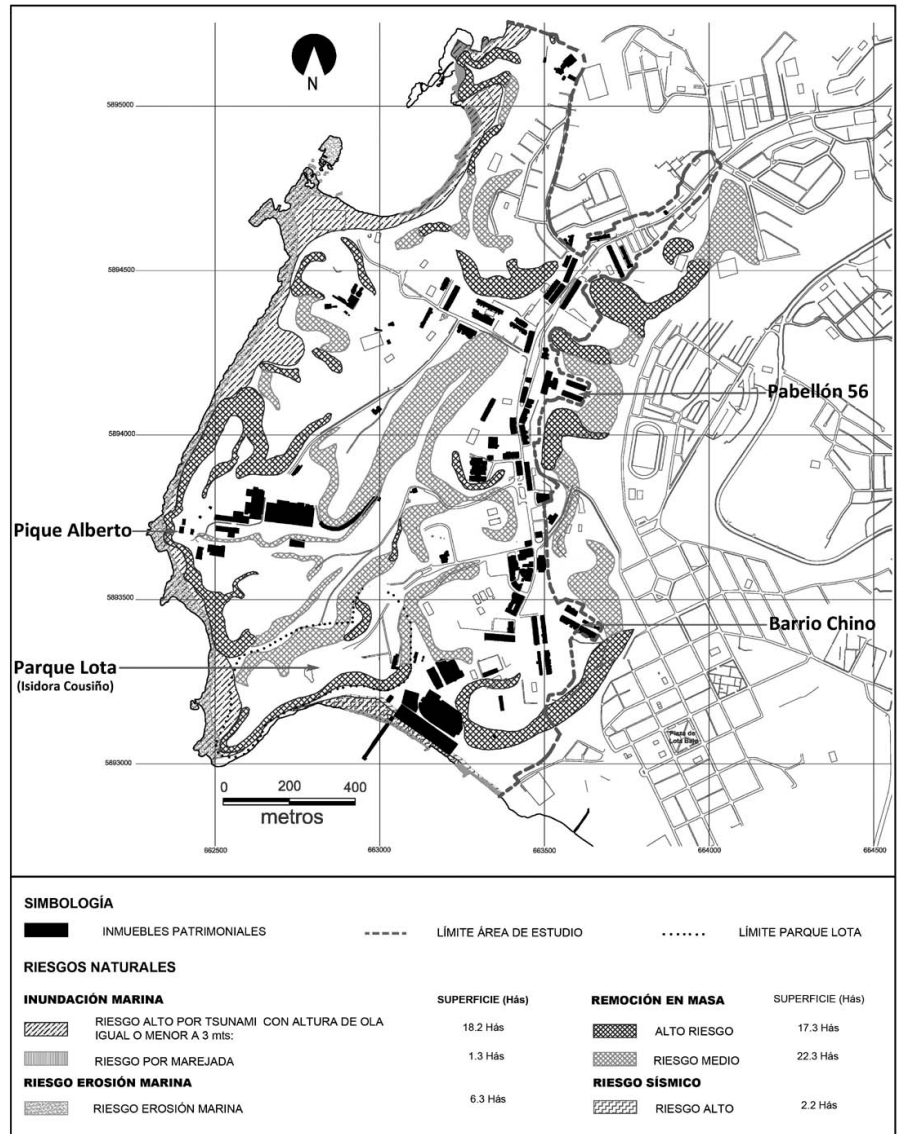

Fuente: Elaboración propia a partir de información extraída de Mardones (1997) y Plan Regulador Comunal de Lota (2010). 
Otros parámetros que pueden influir son: la forma y orientación de la falla, la duración del proceso en la fuente sísmica y la profundidad del océano, entre otros.

Los tsunamis de origen cercano, que han afectado a la Región del Biobío, se han presentado asociados a grandes terremotos. La historia regional registra al menos un tsunami altamente destructivo (grado 3) cada 88 años. El último de estos, con epicentro local, fue registrado el 20 de febrero de 1835 . La determinación de las áreas de inundación marina en caso de tsunami, la definió Mardones (1997) a partir de la concurrencia de los siguientes factores: procedencia del frente de onda desde el SO (sector más común registrado por la historia sísmica), morfología submarina y las condiciones topográficas y morfológicas de las Ilanuras litorales. Siendo los sectores de más alto riesgo las Ilanuras litorales, especialmente aquellas que no cuentan con cordones litorales que actúen como barrera frente al desplazamiento de la ola. En este contexto, el área patrimonial de Lota, prácticamente, no se ve afectada por este riesgo, a excepción del sector del muelle e instalaciones portuarias.

Otro factor importante para la evaluación de este riesgo es el cálculo de la altura de la ola a su llegada a la costa. De acuerdo con Mardones (1997) y el Plan Regulador Comunal (2010), se ha calculado que la ola de un tsunami de este tipo sería de aproximadamente 5 metros en las bahías y de más de 9 metros en las penínsulas con costas rocosas altas.

En relación a las marejadas, los sectores patrimoniales afectados también corresponden al muelle de Lota e instalaciones portuarias emplazadas en el borde costero.

\section{Riesgos antrópicos derivados de la actividad minera}

Además de los riesgos naturales, se identifican una serie de riesgos antrópicos asociados a la actividad minera. Estos riesgos incrementan la peligrosidad de las amenazas naturales, antes descritas. Estos son: i) riesgos asociados a la presencia de pirquenes; y ii) almacenamiento de sustancias peligrosas.
En la Figura $\mathrm{N}^{\circ} 7$ se observan las superficies afectadas por tipo de riesgo antrópico, constatándose que 'los riesgos por presencia de pirquenes' son los que presentan mayor peso, en términos de superficie expuesta.

Los pirquenes son sectores de extracción carbonífera, ya sea legal o clandestina. La presencia de antiguos pirquenes, destinados a la explotación minera subterránea, incrementa la peligrosidad natural de los procesos de remoción en masa. Esto se produce por las constantes explosiones, así como por la presencia de una extensa red de túneles. Ambos factores generan una gran inestabilidad en el suelo, la cual -unida al paso de una onda sísmica- puede desencadenar importantes desprendimientos de ladera o subsidencia; y consecuentemente, generar graves pérdidas y destrucción en viviendas e infraestructura. Las explotaciones de pirquenes de Lota Alto, históricamente han activado en las poblaciones del borde costero una serie de desprendimientos de terreno, derrumbes e inestabilidad de los suelos.

Otros riesgos asociados a la presencia de pirquenes son: caídas accidentales en pirquenes no clausurados, derrumbes por relleno y clausura inadecuada, salida de gases de mina $y$, por último, subsidencia diferencial del terreno, debido a los vacíos generados por la explotación subterránea. En cuanto

Figura $\mathrm{N}^{\circ} 7$

Superficie afectada por riesgo antrópico (hectáreas)

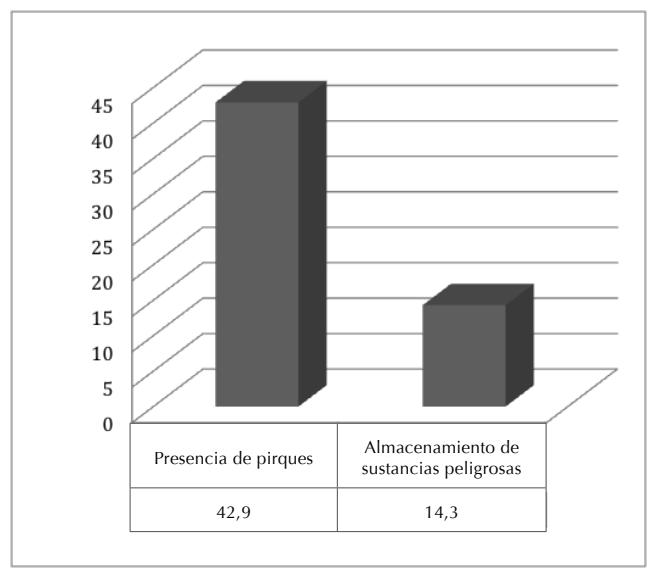

Fuente: Elaboración propia 
a la emisión de gases, el año 1997, cuando se cerró la mina en Lota Alto, la Empresa Minera ENACAR clausuró todos los piques mineros ${ }^{22}$. A partir de esa fecha se realizan controles semanales para medir el nivel de gases y de agua de las galerías. Los resultados de las mediciones son informados al Servicio Nacional Geológico y Minero de Chile (SERNAGEOMIN), e indican que los niveles, tanto de agua como de gases, han sido aceptables, por cual no se ha requerido ningún tipo de intervención.

Por otra parte, muchos pirquenes se han desarrollado históricamente en forma clandestina, desconociéndose su localización exacta. De manera aproximada, el estudio del Plan Regulador elaborado por la Universidad

22 La única excepción fue el Chiflón del Diablo que pasó a manos de Fundación Chile. del Bío-Bío, en 1997, identifica dos zonas de pirquenes en el área de estudio: i) Sector La Conchilla; y ii) Zona frente a población Caleros Sur (Figura $\mathrm{N}^{\circ} 8$ ).

En el presente artículo se ha identificado como zona de riesgo por pirquenes a toda el área en la cual continúan las explotaciones ${ }^{23}$. Esto incluye, prácticamente, todo el borde costero del área patrimonial y el sector localizado al poniente de la población Bannen. No obstante lo anterior, SERNAGEOMIN se encuentra desarrollando estudios específicos en las localidades urbanas más afectadas.

Entre los sitios y elementos patrimoniales potencialmente afectados por este riesgo, se

\footnotetext{
${ }^{23}$ De acuerdo a lo indicado tanto por las autoridades locales como por el Estudio de Diagnóstico del nuevo Plan Regulador Comunal.
}

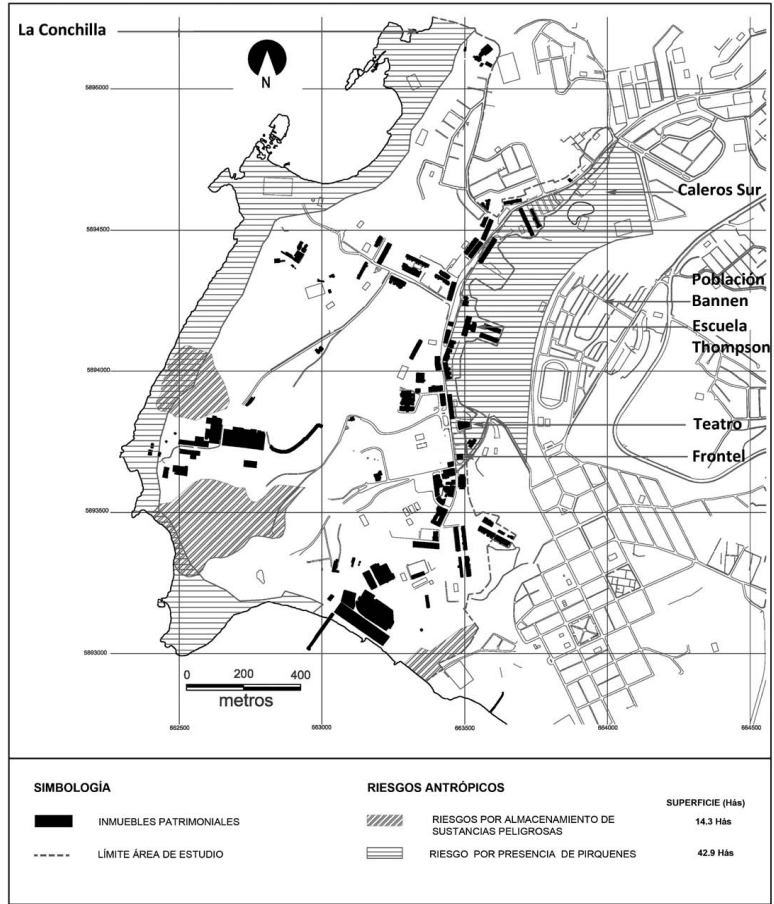

Fuente: Elaboración propia a partir de información extraída de Plan Regulador Comunal (1997). 
encuentran: el borde costero de Lota Alto, la zona industrial de la ex mina y las edificaciones localizadas al costado oriental de la histórica Avenida Carlos Cousiño. Dentro de estas, se cuentan: diversos pabellones ${ }^{24}$, la escuela Thompson Mathews, el teatro de Lota y el edificio Frontel.

Existe riesgo por almacenamiento de sustancias peligrosas, principalmente en dos áreas: en torno a los piques Alberto y Carlos $y$, en menor medida, en el costado del muelle de Lota. Los dos primeros corresponden, hoy en día, a verdaderos cerros de considerable altura, los cuales están siendo poblados por diversas especies vegetales y arbóreas, nativas e introducidas (Figura $N^{\circ}$ 9).

Los principales riesgos asociados son los siguientes:

- de incendio, por tratarse de material inflamable y autocomburente;

- de remoción en masa, potenciado por la presencia de sismos, tsunamis, marejadas, precipitaciones intensas (en el periodo invernal) $y / o$ la presencia de un flujo de agua intermitente, por bloqueo del drenaje de la quebrada;

- contaminación del sistema hídrico por escurrimiento superficial y percolación a las napas subterráneas; y contaminación de la bahía con residuos sólidos suspendidos

Los residuos pueden llegar al mar por tres razones: i) por derrumbe de la pila de carbón aledaña al mar; ii) por drenaje de la quebrada adyacente, que acarree al mar los residuos finos de carbón y tosca; y/o iii) por el acarreo de residuos, producto de un tsunami.

Los sectores más afectados por el riesgo de almacenamiento de sustancias peligrosas, son la ex área industrial de ENACAR y el parque de $\operatorname{Lota}^{25}$. Se debe señalar que en dicho sector existe almacenamiento de explosivos, cuyo riesgo es claro; sin embargo, el almacenamiento de este producto, actualmente, es limitado y en vías de eliminación.

\footnotetext{
24 Pabellones números: 20, 22, 26, 28,30, 37, 49, 50, 55,56 y $68 \mathrm{~B}$.

${ }^{25}$ Ambos son actualmente propiedad de la CORFO.
}

\section{Efectos del terremoto del 27 de febrero} de 2010

El último evento sísmico constituye un ejemplo a analizar, dado que sus impactos se relacionan y se explican tanto por procesos naturales como por cambios ambientales provocados por la actividad minera. Se identifican dos grandes zonas afectadas. La primera, está constituida por una serie de lugares a lo largo del borde costero; y la segunda, está localizada al interior del área patrimonial, en las zonas del histórico Barrio Chino y la avenida Carlos Cousiño.

El borde costero se vio afectado por procesos de remoción en masa y agrietamiento del terreno, los cuales se intensificaron y activaron por el movimiento sísmico. Dichos daños se explican tanto por factores naturales como antrópicos. Dentro de los procesos naturales se distinguen áreas con peligrosidad alta, por tratarse de escarpes de erosión y de falla, con pendientes convexas superiores a $30^{\circ}$, y constituidos por mantos meteorizados con sedimentos incoherentes e hidratados. Paralelamente, se trata de sectores del borde costero, que se encuentran sometidos a una intensa erosión marina, lo que potencia más aún el riesgo. Desde el punto de vista antrópico, la presencia de pirquenes contribuyó a agudizar los deslizamientos, derrumbes y agrietamientos del terreno. Las áreas patrimoniales afectadas fueron: el sector residencial aledaño al Chiflón del Diablo, sectores aledaños al pique Alberto, sector industrial ENACAR-pique Carlos (en punta piquete) y el parque Isidora Cousiño (Figura № 10).

Al interior del área patrimonial, el Barrio Chino y la avenida Cousiño también se vieron afectados por procesos de remoción en masa y agrietamientos del terreno. En el Barrio Chino, el riesgo de remoción se explica por la edificación en áreas de elevadas pendientes, escasa cobertura vegetal y condiciones sedimentológicas (caracterizada por la presencia de mantos meteorizados y sedimentos incoherentes e hidratados). Los sectores que fueron afectados son los pabellones 6, 8, 12 y el sector mirador. En la avenida Carlos Cousiño, las zonas afectadas se relacionan con la ubicación sobre áreas de riesgo de remoción en masa (alto y medio), presencia de pirquenes y un suelo constituido por 
material de relleno (proveniente de escoria y de desechos de la actividad carbonífera). La activación de desplazamientos y movimientos de terreno ha generado el deterioro de los inmuebles de valor patrimonial, asentados en el sector.

\section{Propuesta de manejo ambiental y patrimonial del paisaje minero}

A partir de estos resultados se proponen las siguientes medidas, para abordar integralmente la puesta en valor del patrimonio y el riesgo ambiental, asociado al paisaje minero.

En primer lugar, se sugiere utilizar el concepto de "unidades de paisaje" (UP) planteado por Muñoz-Pedreros (2004), a un proceso integrado de gestión ambiental/patrimonial de la ex área minera. El concepto de UP ha sido definido como las divisiones espaciales que cubren un territorio a estudiar. Las UP se establecen en base a "los aspectos visuales o de carácter de los factores considerados como definitorios del paisaje" (Muñoz-Pedreros, 2004: 142). Este procedimiento involucra las siguientes fases: (a) determinar el componente central, o más representativo del área de estudio; (b) cartografiar el área de estudio generando unidades homogéneas en base al elemento central escogido; y (c) agregar los componentes restantes del paisaje a las unidades homogéneas ya generadas. Al adaptar esta metodología al área patrimonial minera de Lota Alto, se identifican los siguientes componentes centrales: el tejido construido y el relieve. Se consideró que el tejido construido era un componente central, ya que los tipos de tejido presentes en el área, expresan las actividades esenciales del paisaje minero: la habitación y la producción; y porque además, en el caso de Lota, los diversos tipos de tejido establecen una asociación simbiótica con el relieve. De tal manera, se identifican las siguientes unidades de paisaje (Cuadro $\mathrm{N}^{\circ}$ 2 y Figura $N^{\circ} 11$ ).

En segundo lugar, se propone utilizar una matriz en la cual se confronten: los valores patrimoniales y objetivos de la puesta en valor, de cada UP; con las restricciones derivadas de los riesgos y los objetivos de mitigación.
A partir de la consideración de ambos aspectos, se proponen las siguientes medidas específicas a considerar para la puesta en valor, y la reutilización cultural y turística del área patrimonial en Lota.

Figura $\mathrm{N}^{\circ} 9$

Acopio de tosca en el entorno a los piques Alberto y Carlos

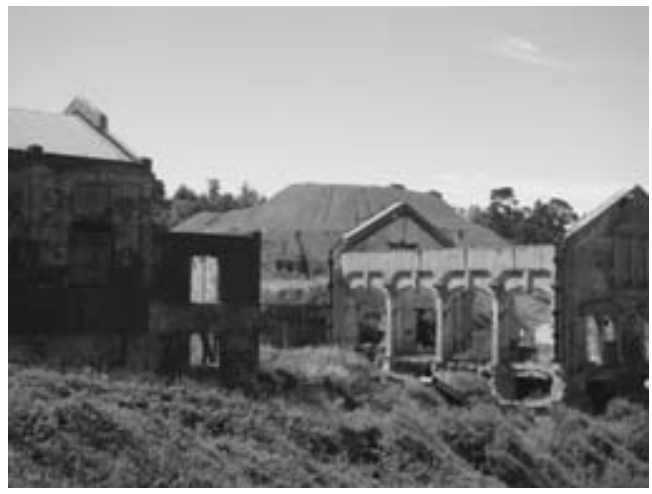

Fuente: Colección propia de las autoras.

Figura $\mathrm{N}^{\mathrm{o}} 10$

Remoción en masa en sector industrial pique Carlos

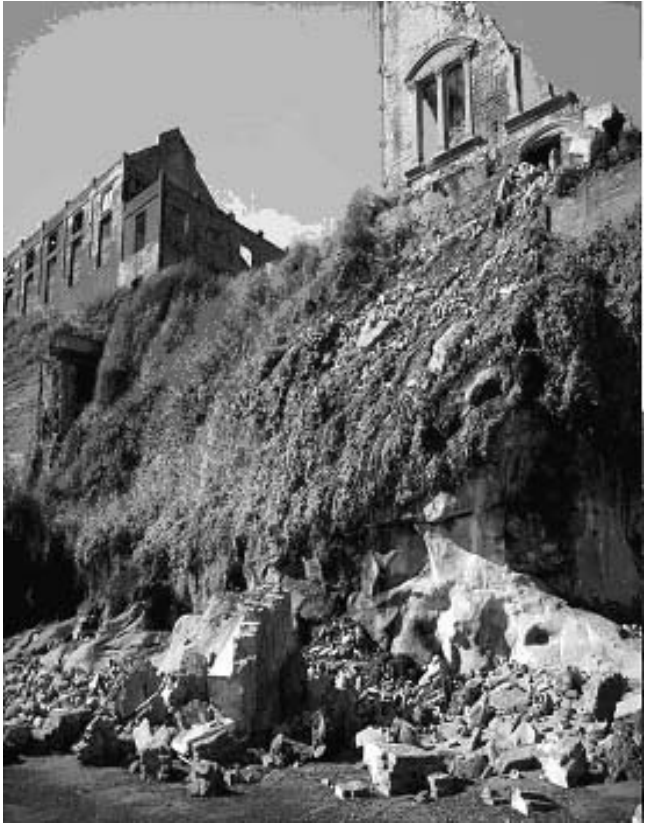

Fuente: Colección propia de las autoras. 
Cuadro $\mathrm{N}^{\circ} 2$

Unidades de paisaje a partir del tejido construido y el relieve como componentes centrales

\begin{tabular}{|c|c|}
\hline $\begin{array}{l}\text { UP } 1 \text { Paisaje industrial costero } \\
\text { Piques } \\
\text { Otras instalaciones industriales } \\
\text { Accesos a túneles subterráneos } \\
\text { Ex líneas de trenes de carga }\end{array}$ & $\begin{array}{l}\text { UP } 3 \text { Paisaje del asentamiento minero } \\
\text { Pabellones mineros } \\
\text { Edificios de equipamiento } \\
\text { Espacios públicos y miradores } \\
\text { Elementos de uso colectivo }\end{array}$ \\
\hline $\begin{array}{l}\text { UP } 2 \text { Paisaje del muelle } \\
\text { Muelle } \\
\text { Vestigios de la fábrica de Lota Green } \\
\text { Cinta transportadora } \\
\text { Otras instalaciones anexas } \\
\text { Accesos a túneles }\end{array}$ & $\begin{array}{l}\text { UP } 4 \text { Parque de Lota } \\
\text { Jardines } \\
\text { Senderos } \\
\text { Miradores } \\
\text { Construcciones }\end{array}$ \\
\hline
\end{tabular}

Fuente: Elaboración propia.

Figura $N^{\circ} 11$

Unidades de paisaje en la zona patrimonial de Lota Alto

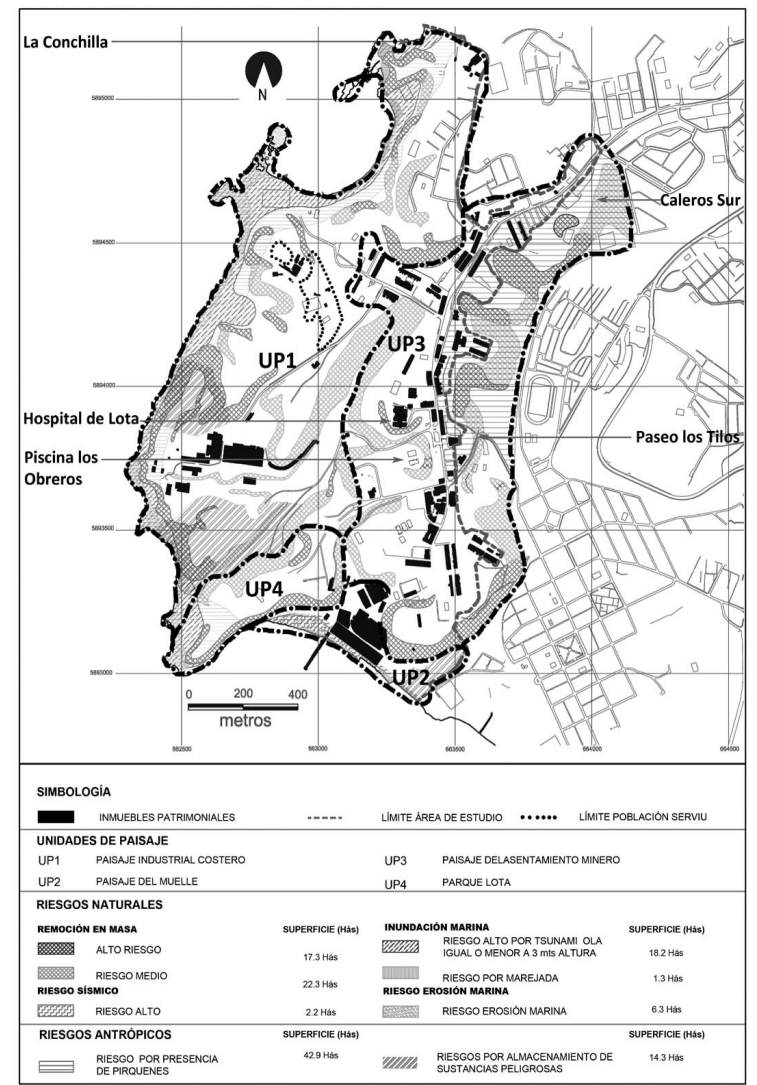

Fuente: Elaboración propia. 


\section{UP 1: Paisaje industrial costero y UP 2: Paisaje del muelle}

Estas áreas contienen valor histórico, por su relación con el desarrollo minero industrial en la zona; valor afectivo para la comunidad, en tanto simbolizan la época del auge minero; valor urbano, como hitos destacados en la imagen del área; y por último, valor paisajístico, dada la calidad y belleza del paisaje costero.

El proceso de reutilización debería considerar los siguientes objetivos: i) la reocupación de las ex instalaciones industriales y el muelle, para usos compatibles con los objetivos de preservación, preferentemente usos culturales, turísticos o educativos, que constituyan un impulso para el desarrollo del turismo de patrimonio minero; ii) la habilitación de lugares de contemplación del paisaje costero, en el entorno de los piques; y iii) el reforzamiento de las conexiones territoriales entre estas zonas y el asentamiento, y entre las instalaciones industriales.

Por otra parte, estas zonas presentan importantes restricciones. En general se trata de áreas abandonadas, salvo el entorno al pique Grande o pique Luis, donde existe una población SERVIU de data reciente ${ }^{26}$. Los objetivos de mitigación deberán enfocarse fundamentalmente a proteger frente a los riesgos de remoción en masa y almacenamiento de sustancias peligrosas a: i) las personas y la propiedad, en sectores habitados; y ii) a las instalaciones patrimoniales, en el resto del área. Adicionalmente, la zona del muelle debe ser protegida frente al riesgo de tsunami y erosión marina.

Por lo tanto se proponen las siguientes acciones de puesta en valor:

- Normar las condiciones de ocupación del entorno a los piques, de manera de asegurar que sigan destacándose en la imagen urbana; preservando su preeminencia visual desde el asentamiento y las zonas aledañas.

26 A principios del año 2000.
- Habilitar senderos que recojan caminos significativos de la época minera (ej.: el camino desde los pabellones mineros hasta las jaulas de descenso a las galerías subterráneas, antiguos túneles y líneas ferroviarias, etc.) y que promuevan las vistas y la contemplación del paisaje.

- Restaurar e instalar nuevos usos en las instalaciones abandonadas, que potencien el turismo cultural (ejemplos: museos temáticos, talleres para producción artesanal, centros culturales o educativos, etc.).

En cuanto a los riesgos de remoción en masa y por presencia de pirquenes, se proponen las siguientes medidas de mitigación:

- Condicionar la ocupación, a la aplicación de medidas de mitigación y estudios de suelo.

- Ante situaciones de subsidencia, producto de excavaciones subterráneas, aplicar medidas de estabilización del suelo para evitar o mitigar la amenaza de derrumbes. Estas incluirán la protección y forestación de las laderas, y la ubicación de vías de drenaje de aguas lluvias.

- Construir muros de contención, con vías de evacuación de aguas lluvias, en sectores poblados y en el entorno de las instalaciones industriales a ser reutilizadas turísticamente.

- Implementar vías de acceso para los visitantes (senderos, ciclovías, caminos, etc.).

- Demarcar, señalizar e implementar barreras de protección en zonas de riesgo medio y alto de derrumbes, especialmente en sectores de acantilados del borde costero, cornisas y escarpes pronunciados, los cuales, junto con presentar alta peligrosidad por condiciones de pendientes, están sometidos a una fuerte erosión marina, lo que intensifica la probabilidad de desplome de grandes bloques de rocas sobre las estrechas playas.

- Finalmente, se propone prohibir excavaciones de cualquier tipo a los pies de las laderas. 
Para mitigar el riesgo por almacenamiento de sustancias peligrosas se propone: compactar los depósitos y estabilizar los suelos; implementar barreras de protección de derrumbe y demarcar senderos a fin de permitir el tránsito y las actividades de observación de manera segura. De igual modo, se propone realizar trabajos de drenaje de los depósitos, e instalar colectores de filtraciones y sistemas de contención de agua.

Finalmente, se proponen las siguientes medidas para mitigar los riesgos del tsunami y la erosión marina, que afectan a una delgada faja al pie de los acantilados y en la zona del muelle. Para el riesgo de tsunami se propone: i) actualizar el Plan Regulador Comunal a fin de integrar dicha amenaza ${ }^{27}$; ii) implementar estrategias de amortiguación del impacto en las zonas en las cuales se decida instalar nuevos usos turísticos (tales como muro rompeolas o zonas arborizadas); iii) condicionar las nuevas construcciones al uso de materiales sólidos (tales como albañilería y/u hormigón) con plantas bajas exentas; y iv) prohibir la instalación de usos críticos tales como: viviendas y servicios de salud y de emergencia en zonas de alta peligrosidad. En el caso de zonas de erosión marina, se recomienda prohibir totalmente su ocupación, e incrementar la superficie vegetada que contribuye a estabilizar la ladera.

\section{UP 3: Paisaje del asentamiento minero}

El asentamiento minero presenta importantes restricciones, dadas fundamentalmente por el riesgo de remoción en masa. Los objetivos de la mitigación deberían enfocarse a proteger a los habitantes y la propiedad patrimonial; y a permitir un uso seguro de los espacios abiertos tanto por parte de los habitantes como de los visitantes. Algunos de los lugares principales a proteger son los siguientes:

- Las vías que vinculan el asentamiento con las zonas industriales y con Lota Bajo,

\footnotetext{
${ }^{27}$ Esta incorporación será posible a partir del reciente estudio de riesgo realizado por la Universidad del Bío-Bío a partir del terremoto del 27/2/2010, que reemplazará la anterior zonificación del tsunami provista por el SHOA, que se efectúo a partir del tsunami del año 1835.
}

las cuales atraviesan las zonas con riesgo de remoción. Dentro de estas se destaca el paseo de Los Tilos, identificado como uno de los espacios patrimoniales más relevantes del área de estudio (SURPLAN, 2005).

- El borde oriente del asentamiento, que limita con la ladera ubicada entre Lota Alto y Lota Bajo. Estos espacios, si bien constituyen un 'detrás' que no se percibe desde la Avda. Cousiño, resultan de importancia en términos de asegurar la estabilidad de las viviendas y equipamientos (muchos de ellos de gran valor patrimonial) ubicados al costado oriente de la avenida.

- El entorno del ex hospital de Lota.

- El sitio de la ex piscina de obreros.

Por lo tanto, se proponen las siguientes acciones de puesta en valor:

- Normar las condiciones de ocupación del área de manera de asegurar la preservación de los valores arquitectónicos de los edificios patrimoniales; asegurar asimismo que las nuevas edificaciones no afecten la imagen urbana, proteger las vinculaciones entre el espacio público y el paisaje lejano; y finalmente, preservar la preeminencia visual de los edificios singulares de equipamiento.

- Restaurar e instalar nuevos usos en los edificios de equipamiento subutilizados o abandonados de manera de potenciar usos compatibles con los valores patrimoniales del edificio y en general con la valorización del área minera. Se proponen usos culturales, turísticos y educativos, que potencien el turismo cultural en el área.

Se proponen además las siguientes medidas de mitigación:

- Prohibir la ocupación de laderas con alto riesgo de remoción en masa y condicionar la ocupación en aquellas zonas que presenten riesgo medio. 
- Estabilización de laderas mediante reforestación en el sector oriente del área de estudio.

- Protección u otras obras de estabilización de laderas (cobertura vegetal y muros de contención) en principales vías de conexión que comunican con la zona industrial, el muelle y Lota Bajo.

- Estabilización de laderas mediante muros de contención, vegetación u otras obras de estabilización en el entorno del hospital y la ex piscina de obreros.

\section{UP 4: Parque de Lota}

La significancia del parque de Lota se deriva de su valor como expresión de las ideas paisajísticas imperantes en Europa, adaptadas al contexto local (en especial a una accidentada topografía) y en el cual se da cabida a una diversidad de plantas exóticas, junto con otras autóctonas. De igual modo, se valora la condición del parque como 'mirador' hacia la zona del muelle de Lota y los piques lejanos; y por último, se valora su connotación, que fue paulatinamente evolucionando desde un uso inicial exclusivo de la familia Cousiño, hasta un uso cada vez más frecuente como espacio de encuentro de la comunidad lotina. El parque se encuentra actualmente protegido por su condición de Monumento Nacional; y a partir del 1 de enero de 2012 su mantención está a cargo de la Corporación Baldomero Lillo, como entidad operadora del Circuito Turístico Lota Sorprendente ${ }^{28}$; ambos factores constituyen un impulso para la preservación de sus valores patrimoniales.

Por otra parte, el parque presenta diversas zonas de riesgo, localizadas fundamentalmente en sus bordes: riesgo de erosión en sus costados, asociado a la presencia de fuertes pendientes; y riesgo de erosión marina y tsunami hacia su extremo sur poniente, en el encuentro del parque con el mar. Por lo tanto, los objetivos de mitigación deberían ser fundamentalmente: la protección de las personas y de la propiedad patrimonial en

${ }^{28}$ Antes de esa fecha estaba a cargo de la Fundación Chile. las zonas de borde, posibilitando una reocupación cultural, turística y de esparcimiento segura. Se proponen las siguientes medidas de mitigación: protección de los bordes del parque, con vegetación; y estabilización de laderas mediante aterrazamiento y vegetación, u otras obras de estabilización, en el extremo sur poniente.

\section{Conclusiones}

Los resultados del estudio permiten constatar que el área de Lota Alto presenta un importante potencial para desarrollar un turismo cultural de patrimonio minero. Por otra parte se constata la presencia de riesgos ambientales que se explican tanto por sus condiciones naturales como por factores antrópicos, que los han amplificado.

El principal factor natural desencadenante de riesgos, se relaciona con las características climáticas y geomorfológicas del emplazamiento. A ellas se agregan los factores antrópicos, los que incrementan e intensifican los riesgos por dos causas fundamentales. En primer lugar, por la actividad minera en sí; y en segundo lugar, por un inadecuado proceso de cierre y remediación de impactos en la fase postminera, junto a una explotación industrial y urbanización que ignora las condiciones del soporte natural y la capacidad de acogida del territorio. Vastos sectores de la zona patrimonial se ocuparon sin considerar las características del soporte físico, en la asignación de usos y en la forma como estos interactúan con el sitio natural en el cual se hallan instalados. Específicamente, la excavación de túneles y galerías subterráneas y la acumulación de tosca e inadecuados procesos de compactamiento de terreno, han amplificado la probabilidad de ocurrencia de derrumbes y deslizamientos. Luego, al efecto de los procesos extractivos en sí, se ha sumado la cercanía -e incluso en algunas zonas la superposición- de las áreas habitadas con las antiguas zonas de explotación. Este tipo de ocupación urbana, que fue promovido desde los inicios del asentamiento, por las diversas administraciones de las compañías mineras (y que por lo demás es una de las características esenciales del modelo de ciudad obrera), ha tenido una desafortunada continuidad en la época contemporánea. Este hecho resulta 
patente, por ejemplo, en las últimas poblaciones SERVIU, construidas en la ex zona industrial, aledaña al pique Grande.

Otro factor que suma otro tipo de riesgo, es la ubicación del asentamiento minero en una zona sísmica y costera. De ahí la presencia de fajas de terreno expuestas a la amenaza de tsunami y de erosión marina. Por otra parte, en este caso, el accidentado relieve protege la mayor parte del área patrimonial de la amenaza de tsunami, gracias a su altura con respecto al mar. Una excepción a esta situación de resguardo, se produce en el ex muelle, el cual -dado su uso- se sitúa en una relación mucho más expuesta. Esto nos lleva también a plantear la necesidad de definir una estrategia particular para este tipo de instalaciones, en las cuales se conjugan no solo importantes valores patrimoniales, sino también un alto potencial paisajístico, que podría contribuir de manera sustantiva a la reocupación cultural y turística que se busca impulsar.

En síntesis, la investigación ha permitido constatar la imperiosa necesidad de abordar la problemática patrimonio minero en la fase postextractiva, y en particular en la necesidad de perfeccionar estrategias integradas de puesta en valor y de mitigación de los impactos ambientales. Solo esta visión holística permitirá impulsar iniciativas sostenibles de reutilización de estas áreas, en la fase postindustrial.

\section{Referencias bibliográficas}

ASTORQUIZA, O. Lota: Antecedentes Históricos, con una monografía de la Compañía Minera e Industrial de Chile. Concepción: Sociedad Imprenta y Litografía, 1929.

ARAVENA, J. y BETANCUR, C. Reconversión laboral del carbón. Santiago de Chile: Tesis de Grado, Literatura en Sociología, Universidad Arcis, 1995.

AYALA-CARCEDO, F.J. Patrimonio Natural y Cultural y Desarrollo Sostenible: El patrimonio Geológico y Minero. En: RÁBANO, I. (editora). Patrimonio geológico y minero en el marco del desarrollo sostenible: ponencias presentadas en el Congreso Internacional sobre Patrimonio Geológico y Minero en el Marco del Desarrollo Sostenible y V Sesión Científica de la SEDPGYM. Madrid: Instituto Geológico y Minero de España, 2000.

AYALA-CARCEDO, F. Estrategias para la reducción de desastres naturales. Investigación y Ciencia, 1993, № 200, p. 6-13.

AYALA-CARCEDO, F. et al. Riesgos Geológicos. Madrid: Instituto Geológico y Minero de España, 1988.

CARVAJAL, D. y GONZÁLEZ, A. La Contribución del Patrimonio Geológico y Minero al Desarrollo Sostenible. En: VILLAS BÔAS, G. y DE ALBUQUERQUE, A. (editores). Patrimonio Geológico y Minero en el Contexto del Cierre de Minas. Río de Janeiro: CETME/ ISAAC/Cyted, 2003, p. 27-49.

CLARK, A. \& COOK J. An International Overview of Legal Frameworks for Mine Closure. 2005. Disponible en Internet: http:// www.irdc.org.

COLE, D. Exploring the Sustainability of Mining Heritage Tourism. Journal of Sustainable Tourism, 2004, Vol. 12, N66, p. 480-494.

FLAGEOLLET, J.C. Les mouvements de terrain et leur prevention. París: Editorial Masson, 1989.

GUEREMY, P. Rapport introductif. Actes de Premier Forum française de Geomophology. Revue de Geomorphology Dynamique, 1987, Vol. 36, №3, p. 30-45.

JANSEN-VERBEKE, M. Industrial heritage: a nexus for sustainable tourism development. Tourist Geographies, 1999, Vol. 1 (N¹), p. 70-85.

LARRAÍN, P. y SIMPSON-HOUSLEY, P. Percepción y prevención de catástrofes naturales en Chile. Santiago de Chile: Universidad Católica de Chile, 1994.

LARRAÍN, P. El sistema natural en la planificación urbana chilena. Revista Geografía Norte Grande, 1992, № 19, p. 58-68.

LEARY T. \& SCHOLES E. Authenticity of place and voice: Examples of 
industrialheritage preservation and interpretation in the US and Europe. The Public Historian, 2000, 22, N³, p. 49-66.

LOPEZ, M.I. Proyecciones del Patrimonio Minero en Chile, la reocupación cultural y turística como estrategia de revitalización, el caso del territorio minero del Golfo de Arauco. Madrid : Tesis Doctoral, ETSAM, UPM, 2010.

MARDONES, M. y VIDAL, C. La zonificación y evaluación de los riesgos naturales de tipo geomorfológico: un instrumento para la planificación urbana en la ciudad de Concepción. EURE, 2001, Vol. XXVII, № 81, p. $97-122$.

MARDONES, M. Estudio de Riesgos naturales. En: UNIVERSIDAD DEL BÍO-BÍO. Plan Regulador Comunal de Lota. Lota: Municipalidad de Lota-MINVU, 1997.

MARDONES, M. et al. Zonificación y evaluación de riesgos naturales, en el área metropolitana de Concepción. Concepción: Informe Final FONDECYT 92-0251, 1995.

MUÑOZ, M.D.; SANHUEZA R.; PÉREZ L.; SEGUEL L. y LÓPEZ, M.I. Identidad, Memoria Colectiva y Participación en el Proceso de Transformaciones Contemporáneas del Asentamiento Minero de Lota Alto. Concepción: Informe final Proyecto FONDECYT No 1044098, 2005.
MUÑOZ-PEDREROS, A. Evaluación de Paisaje: una herramienta de gestión ambiental. Revista Chilena de Historia Natural, 2004, $\mathrm{N}^{\circ} 75$, p. $139-156$

MURATA, S.; IMAMURA, F.; KATOH, K.; KAWATA, Y.; YAKAHASHI, S. \& TAKAYAMA, T. Tsunami: To survive from tsunami. Singapore: World Scientific Publishing Co., Advanced Series on Ocean Engineering, 2010, Vol. 32.

ORTEGA, L. The first four decades of the chilean coal mining industry, 1840/1879. Journal of Latin American Studies, 1982, № 14 , p. 1-32.

PUCHE RIAT, O. Patrimonio minerometalúrgico español: arquitectura y paisajes mineros. En: MATA - PERELLÓ, J.M. (editor). Actas del IV Congreso Internacional sobre patrimonio geológico y minero. VIII sesión científica de la SEDPGYM, sept., Aragón Vivo, SL Teruel, 2003.

SABATÉ BEL, J. Paisajes Culturales como Recurso Básico para un nuevo modelo de desarrollo. URBAN, 2004, No 9, p. 8-29,

SUR PLAN LTDA. y ELIASH, H. Estudio de Identificación de Zonas de Conservación Histórica en las comunas de Valparaíso, Viña del Mar, Independencia, Nuñoa, San Miguel, Lota y Valdivia. Santiago de Chile: Ministerio de Vivienda y Urbanismo, 2005. 
